\title{
A video game based hand grip system for measuring muscle force in children
}

\author{
Mark Gotthelf ${ }^{1}$, DeWayne Townsend ${ }^{2}$ and William Durfee ${ }^{1 *}$ (D)
}

\begin{abstract}
Background: While new therapies are continuously introduced to treat muscular dystrophy, current assessment tests are challenging to quantify, cannot be used in non-ambulatory patients, or can de-motivate pediatric patients. We developed a simple, engaging, upper-limb assessment tool that measures muscle strength and fatigue in children, including children with muscular dystrophy. The device is a bio-feedback grip sensor that motivates children to complete maximal and fatiguing grip protocols through a game-based interface.

Methods: To determine if the new system provided the same maximum grip force as what is reported in the literature, data was collected from 311 participants without muscle disease (186 M, $125 \mathrm{~F}$ ), ages 6 to 30, each of whom played the four minute grip game once. We compared maximum voluntary contraction at the start of the test to normative values reported in the literature using Welch's unequal variances $t$-tests. In addition, we collected data on a small number of participants with muscle disease to determine if the assessment system could be used by the target patient population.

Results: Of the 311 participants without muscle disease that started the test, all but one completed the game. The maximum voluntary contraction data, when categorized by age, matched literature values for hand grip force within an acceptable range. Grip forced increased with age and differed by gender, and most participants exhibited fatigue during the game, including a degradation in tracking ability as the game progressed. Of the 13 participants with muscle disease, all but one completed the game.

Conclusions: The study demonstrated the technical feasibility and validity of the new hand grip device, and indicated that the device can be used to assess muscle force and fatigue in longitudinal studies of children with muscular dystrophy.
\end{abstract}

Keywords: Muscular dystrophy, Muscle force assessment, Game-playing, Muscle fatigue

\section{Background}

Muscular dystrophy is a group of genetic muscle diseases marked by progressive loss of muscle mass and muscle weakness [1]. Duchenne muscular dystrophy (DMD) is the most common form and is a genetic defect characterized by an absence of dystrophin, a protein that maintains the structure of muscle fibers [2]. DMD is an

\footnotetext{
*Correspondence: wkdurfee@umn.edu

${ }^{1}$ Department of Mechanical Engineering, University of Minnesota, Minneapolis, USA

Full list of author information is available at the end of the article
}

X-linked genetic disorder that primarily affects boys and birth prevalence of DMD among males is estimated at 1 in 5000 [3].

DMD is diagnosed early and progresses steadily [4]. Onset is between two and seven years and a wheelchair is typically needed sometime between the ages of 10 and 14. By the late teens, there is significant loss of upper extremity strength, including the ability to move the arms. Today, with advances in respiratory and cardiac care, many with DMD live into their thirties, although most do not survive past the age of 25 with death typically resulting from respiratory complications. While 
there is no cure for muscular dystrophy, therapies can manage symptoms and slow the evolution of the disease [5-8]. For example, corticosteroids have been shown to moderate disease progression, but are not universally prescribed because of side effects [7,9].

For clinical care of a patient with DMD or for any clinical trial examining new DMD treatments there is a need for quantitative assessment measures to precisely track the progress of the disease or to measure a treatment effect. A sensitive and reliable quantitative assessment tool is needed by clinicians who must track and record the status of their DMD patient to assess a response to therapy. It is needed by clinicians and parents who are seeking full knowledge of a child's clinical status and how that status has changed over time. In addition it is most acutely needed for clinical trials that require a highly reproducible and quantitative assessment of muscle function to determine the therapeutic effect of new treatments.

With the recent and robust history in developing candidate drugs to treat DMD, there has been considerable attention paid to what outcome measures should be used in clinical trials. Examples, some of which are described below, are reported in [10-23] as well as in recent reviews [23-26]. All of these measures have flaws that limit their usefulness for clinical assessments. The device we describe in this paper addresses many of these flaws and is anticipated to provide a reliable quantitative assessment of muscle function in the pediatric DMD patient population.

Because DMD is a muscle disease, the majority of outcome measures test skeletal muscle function. The most common test used is the manual muscle test (MMT), which is performed informally in practically every clinic visit by a DMD patient and performed formally in many DMD clinical studies. For the MMT, the patient voluntarily contracts the muscle against a gravity load or resistance with the examiner determining the response on a $0-5$ scale $[27,28]$. While easy to learn and easy to apply, the reliability, accuracy, and inter-rater reliability of MMT has been questioned [27, 29, 30]. Further, MMT cannot be used to detect small changes in strength seen in a relatively slowly progressing disease such as DMD [20, 31].

Quantitative muscle testing (QMT) measures maximum voluntary contraction using a mechanical or electronic dynamometer that records the reaction force. The quantitative output improves test-retest and inter-rater reliability compared to MMT so long as a standardized protocol is used [20, 32-34]. Systems such as The Richmond Quantitative Measurement System and Kin Com's 125 are examples of more complex QMT devices that have been used in DMD and spinal atrophy studies to measure the strength of several muscles [19, 20, 22, 35]. These systems, however, are costly and require a bulky fixation apparatus which limits their utility in the clinic and in clinical trials.

A common outcome measure used in many DMD studies is the six-minute walk test (6MWT) where the patient walks as far as possible in six minutes on a walking course $30 \mathrm{~m}$ in length [36, 37]. A modified version for children has been developed for use in DMD patients and has been shown to be safe, easy to apply and reproducible [11-13]. The primary limitation of the 6MWT is that it requires ambulation, which means it cannot be used for long term studies or for assessing patients in the later stages of DMD who are in a wheelchair. Further, the patient's motivation to perform the test can impact performance.

The North Star Ambulatory Assessment (NSAA) is a 17 item test of functional abilities that are important for ambulation [14]. The NSAA has been shown to be reliable and to correlate with other measures such as the 6MWT [15-18]. The NSAA can be difficult to quantitate and is limited to patients who are ambulatory. Also the complexity of the NSAA tasks can lower motivation to perform, especially in younger patients, which in turn can influence the score.

For non-ambulatory DMD patients, a recent study concluded that a suite of functional measurements could be used for outcome assessment but also pointed out that there is no consensus on which measures are best [21]. A review of assessment tools for upper limbs also highlighted the need for measures that can be used over the full spectrum of DMD as studies only using 6MWT or NSAA measures cannot follow children who have lost ambulation during the course of the trial [25].

The Performance of the Upper Limb (PUL) is a recent assessment tool that was created specifically for measuring upper limb function in ambulant and non-ambulant patients with DMD [38], and was shown to be reliable in a multi-center trial and to be a useful measure when combined with the 6MWT for ambulatory boys $[39,40]$.

Hand grip is commonly measured in DMD studies and is a good indicator of muscle strength [21, 41]. Generally, grip is measured with a handheld tool such as the Jamar dynamometer, for which there are normative values for children [42] and adults [43]. While hand weakness can be detected in the early stages of DMD, it is only revealed by comparing to control values as the weakness from the disease is counteracted by the normal hand strength that increases in the first decade [41]. Because grip strength can be measured for ambulant and non-ambulant DMD patients and because it is fast and easy to apply, it is useful for short and long-term assessment of muscle function in a child with DMD. Traditional hand grip testing 
depends on patient motivation, which in turn relies on patient engagement. This can be a challenge with a test that uses a hand dynamometer as children with progressive disease can see that their grip strength is decreasing with age.

The standard hand grip test only measures maximum voluntary contraction as an indicator of muscle function. For assessing outcomes related to DMD we believe there may be value in also measuring muscle fatigue as fatigue is prevalent in DMD patients along with loss of strength [4]. In animal models of DMD and in DMD patients there is evidence of defects in the regulation of blood flow in response to contraction [44, 45], which results in the development of functional ischemia, the consequences of which are demonstrated in the extreme levels of fatigue evident in mouse models of DMD following strenuous exercise [46]. Fatigue is commonly reported in patients with DMD [47], but the standard tests reviewed here, including MMT, QMT and the 6MWT, are unable to reliably measure fatigue in DMD patients [48].

Thus there is a need for a simple, engaging upperlimb assessment tool that measures muscle strength and fatigue in children with DMD. In this paper we describe such a device: a game-based hand grip measuring system that is quantifiable, can be performed by patients at all levels of muscle disease progression, including nonambulatory patients, and is fun and motivating for the patient. We describe how the device works and report on the results of a study where the grip strength of people who do not have muscle disease was measured using our device. Our study demonstrates that the new device reports hand grip strength that is consistent with grip strength reported in the literature from normative studies using a traditional grip dynamometer. In addition we report on the use of the measuring system by a small number of patients with neuromuscular disorders, almost all of whom were able to complete the test.

\section{Methods \\ Hand grip system}

The hand grip force measuring system consists of two components: a hand-grip dynamometer that fits into the hand and contains force sensors to measure grip force along with associated sensor conditioning electronics, and a computer-based bio-feedback game that the user plays by squeezing the dynamometer.

The dynamometer (Fig. 1) has two plastic bars bridged by a pair of load cells. The low-force model uses $20 \mathrm{~kg}$ load cells (Phidgets 3134_0) and can measure up to $40 \mathrm{~kg}$ while the high-force model uses $50 \mathrm{~kg}$ load cells (Phidgets 3135_0) and can measure up to $100 \mathrm{~kg}$. Squeezing the bars together causes grip force to be transferred to the sensor whose output is filtered, amplified, and digitized (24-bit at $80 \mathrm{~Hz}$, SparkFun SEN-13261), and then sent to a laptop via a USB connection. The design was intended to be as light weight as possible so that it could be used by children of all ability.

The dynamometers were calibrated using a load frame (MTS QTest QT/10). The devices were compression loaded at a rate of $0.2 \mathrm{~mm} / \mathrm{s}$ to a load of $300 \mathrm{~N}$ for the low force model and $700 \mathrm{~N}$ for the high force model. Regression lines were fit to the force-time data from the load frame and the force-time data from the grip sensor and the line slopes divided to generate a calibration constant. The load test was repeated three times to produce an average calibration constant for the device.

Grip strength was tested by having participants play the Rocket Launch video game, which uses the hand-grip

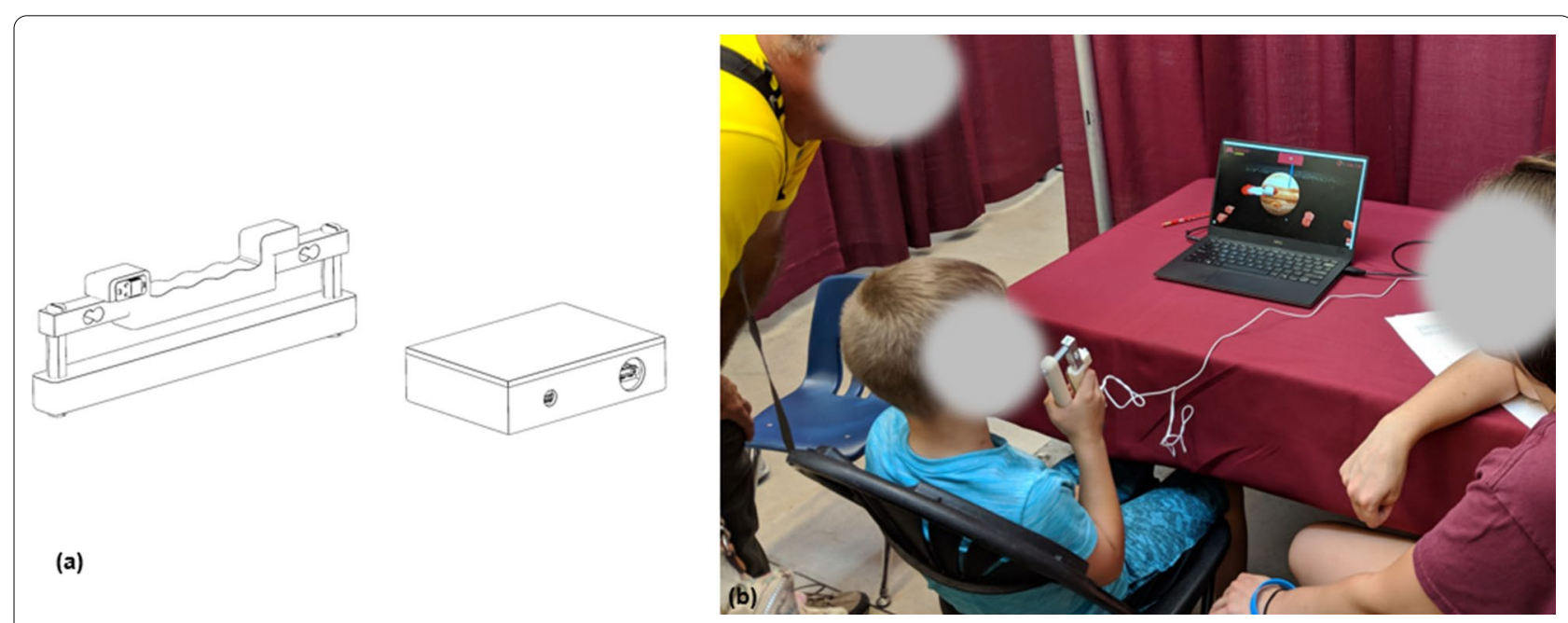

Fig. 1 a Hand-grip dynamometer and associated electronics interface box. b System in use at the 2018 Minnesota State Fair 
dynamometer as a controller. Squeezing and relaxing the dynamometer causes an animated rocket to move up and down on the game screen (Fig. 2). As participants play the game, they are taken through an exercise protocol. For participants, the goal of the game is to score points by staying above the asteroid belt and by flying through the rings that periodically appear (Fig. 2B). The user watches the screen to determine the desired path to earn points. The higher on the screen that the asteroid belt and rings appear the harder the participant must squeeze the dynamometer to earn points. The Rocket Launch application allows the researcher to construct the game exercise protocol by specifying any combination of calibration periods, tracking periods where the user squeezes the handle to move the rocket to the desired path, and rest periods, each of any length. During a calibration period, the user is instructed to squeeze the handle as hard as they can, which causes to rocket ship to launch into the air (Fig. 2A). The initial pre-game calibration period establishes the maximal voluntary contraction (MVC) for grip force, which is used to scale the target forces during the asteroid belt tracking periods. The game is connected to the cloud through a secure link. Game data is stored in a secure database and game parameters can be adjusted remotely, which means that any local laptop can be used to run the game.

The game used to collect data for this study was $265 \mathrm{~s}$ in duration with $5 \mathrm{~s}$ calibration periods at the beginning, middle and end of the game. Following the initial calibration to gather MVC, there was a $15 \mathrm{~s}$ rest period then tracking periods of $40 \%, 60 \%, 80 \%, 60 \%$, and $40 \%$ of the initial MVC, each lasting $15 \mathrm{~s}$ and followed by $5 \mathrm{~s}$ rest periods between each period. Following the last $40 \%$ tracking period was a 15 s rest period. Next came the mid-game determination of MVC. A repeat of the tracking and rest periods followed and the game terminated with a determination of the post-game MVC. Figure 3 shows the timeline for this game.

\section{Validation study}

To validate the grip device as a muscle force assessment tool, we ran a study using participants without muscle disease. The study was run at the University of Minnesota Driven to Discover Research Facility at the 2018 Minnesota State Fair, which is among the largest state fairs in the United States. The study was approved by the University of Minnesota Institutional Review Board (IRB ID: STUDY00003448).

\section{Participants}

Participants were recruited from visitors to the fair. The inclusion criterion was to be in the age range of 6 to 30 years. Exclusion criteria were having an identified neuromuscular disease diagnosis or being unable to follow directions.

\section{Apparatus}

The hand grip dynamometer and Rocket Launch video game described above were used to assess muscle force.

\section{Procedure}

All activities took place during a single 10-min session. Participants or their parents self-reported their age and gender. The participant was seated in front of the screen and instructed to hold the dynamometer with their dominant hand, their elbow bent approximately $90 \mathrm{deg}$ and their wrist in the neutral position. Younger children used the low-force model dynamometer while the rest used the high-force model. Following a brief instruction period, the participant played the Rocket Launch
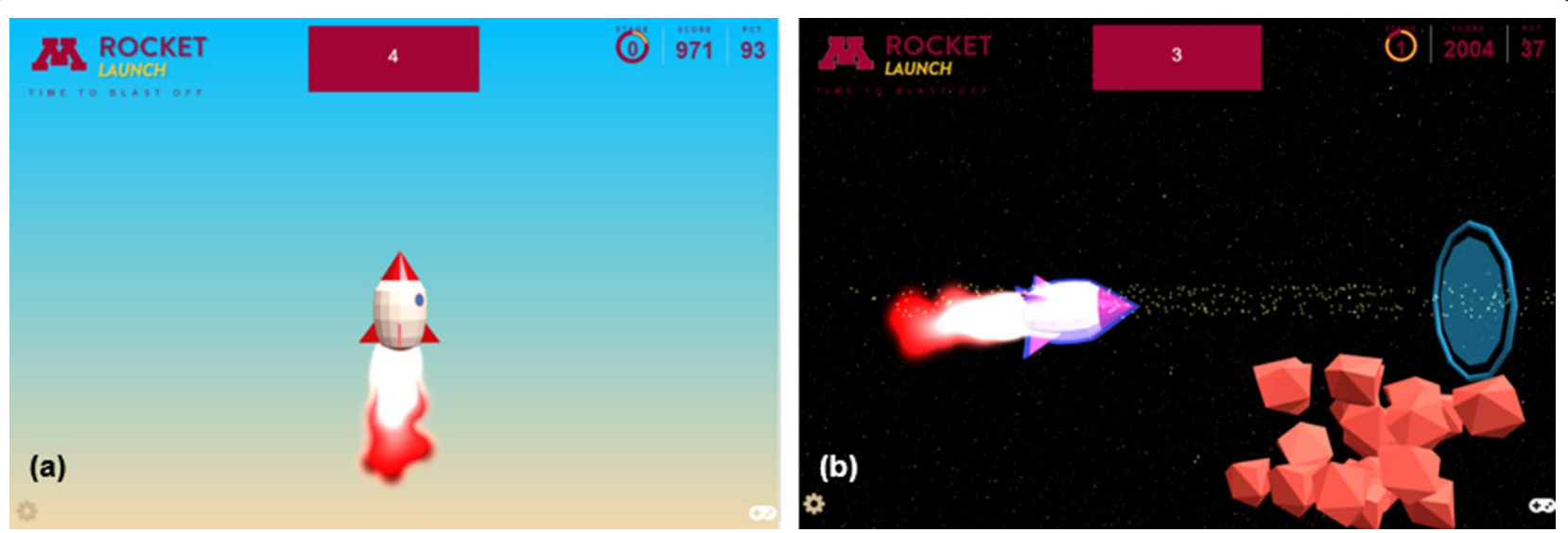

Fig. 2 a Screen shot of the calibration task from the Rocket Launch application. b Screen shot of the tracking task from the Rocket Launch application 


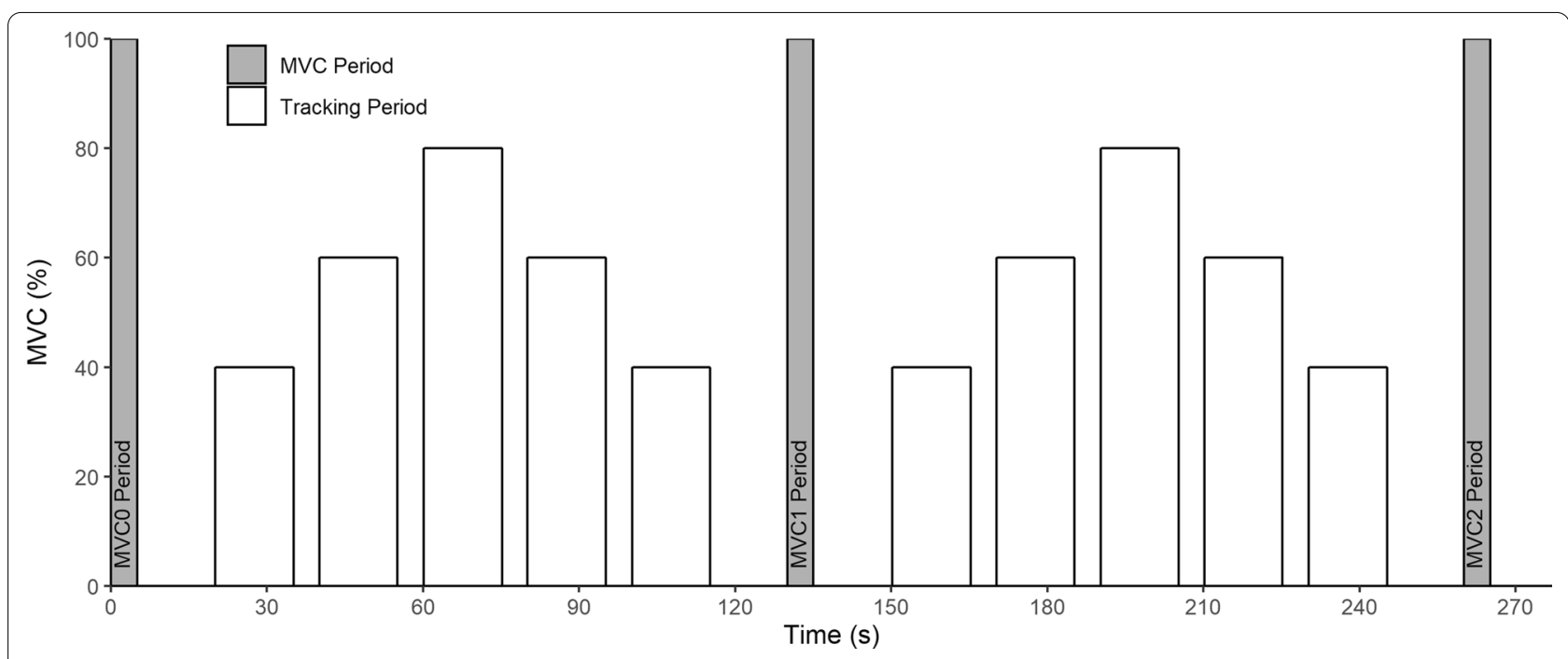

Fig. 3 Task interval time line used in the Rocket Launch game

game, with the game protocol described above. During the three calibration periods, the researcher urged the participant to squeeze as hard as possible (to "launch the rocket"). During the tracking periods positive feedback was provided when the participant was able to earn points by tracking the target.

\section{Data analysis}

Maximum voluntary contraction during the beginning (MVC0), middle (MVC1), and end (MVC2) of the game was determined by finding the maximum grip force during the calibration period and calculating the average of a five point range starting two data points prior to the maximum value. If the maximum force was greater than $125 \%$ of that average the data set was flagged as containing an outlier and was not used for further analysis. (Outliers were present in less than $1 \%$ of the data sets).

During grip force target tracking, root mean square (RMS) tracking error (the difference between the desired trajectory indicated by the location of the rings and the actual trajectory of the rocket) was calculated for each sample using

$$
R M S=\sqrt{(\text { Target } \%-\text { Response } \%)^{2}} .
$$

The total RMS tracking error was the sum of the sampleby-sample error over the period of interest.

Summary statistics (mean, standard deviation (SD), and range) were calculated for age group and gender. The Pearson correlation coefficient was used to measure the correlation between MVC and age and tracking error, and a linear regression model to determine the $R^{2}$ value between MVC and age. ANOVA with post hoc
Bonferroni correction was used to determine if there were any differences between the pre-game, mid-game and post-game MVC readings. A paired $t$-test was used to determine if there was any difference between tracking error during the $80 \% \mathrm{MVC}$ period in the first half of the game and the the $80 \%$ MVC period in the second half of the game.

To validate whether the new device produced MVC readings that were the same as those reported in the literature, we compared our data to data from eight previous studies that assessed hand grip strength in pediatric populations [42, 43, 49-54]. These studies all used a commercially available hand grip dynamometer with six of the eight using the gold-standard Jamar dynamometer. For the comparisons, participants were grouped by age according to the age groupings used by Mathiowetz [42, 43]. Grip force averages and standard deviations were calculated from the eight studies for each age group and sex. Differences for each age group and sex between the initial MVC (MVC0) reported by our device and the literature-based normative data were determined using Welch's unequal variances $t$-tests. (The Shapiro-Wilk normality test was run for each age group in our data and the test statistic showed that the MVCO data points in all groups were approximately normally distributed). All statistical tests were performed using R, version 3.6.3 [55].

\section{Use by people with muscle disease}

To determine if the device could be used by the intended patient population, in addition to the main study we recruited a small number of individuals with muscle disease. This sub-study was approved by the University of Minnesota Institutional Review Board (IRB ID: 
STUDY00001330). The purpose of this part of the project was to determine whether patients, and particularly children with muscular dystrophy, could understand and complete the grip strength game. The number of participants in the sub-study was designed to determine if participants could complete the game and was not powered to provide conclusions about muscle strength or game performance.

\section{Results}

\section{Participants}

Over four days 311 participants were enrolled in the study. Of those, 29 had missing or incorrect data, one did not finish the game, 39 saturated the dynamometer, three had outliers in the initial MVC data and two had data errors in the mid or post-game MVC readings. This left a sample size of 237 participants for the data analysis.

Of the 237 participants 139 (59\%) self-identified as male and $98(41 \%)$ self-identified as female. Table 1 reports the demographics of the participants, mean strength, standard deviation of mean strength, and range of strength, following the age-groups of Mathiowetz [42, 43].

Figure 4 shows one example of dynamometer grip force data from one session. The game has three five-s calibration periods: at the start, middle and end of the game,

Table 1 Characteristics of participants (Age, Gender), and mean, standard deviation and range of grip strength in dominant hand ( $N$ $=237)$

\begin{tabular}{|c|c|c|c|c|c|c|c|c|}
\hline \multirow[t]{2}{*}{ Age } & \multicolumn{4}{|c|}{ Males } & \multicolumn{4}{|c|}{ Females } \\
\hline & $n$ & Mean (N) & $\mathrm{SD}(\mathrm{N})$ & Range & $n$ & Mean (N) & $\mathrm{SD}(\mathrm{N})$ & Range (N) \\
\hline $6-7$ & 10 & 128 & 47 & $73-227$ & 7 & 103 & 27 & 69-141 \\
\hline $8-9$ & 17 & 182 & 50 & $78-273$ & 9 & 161 & 32 & $98-200$ \\
\hline $10-11$ & 26 & 199 & 56 & $121-325$ & 12 & 204 & 42 & $142-290$ \\
\hline $12-13$ & 28 & 256 & 72 & $140-467$ & 17 & 230 & 48 & $155-328$ \\
\hline $14-15$ & 11 & 383 & 138 & $209-660$ & 12 & 296 & 34 & $232-348$ \\
\hline $16-17$ & 5 & 366 & 119 & $223-554$ & 10 & 293 & 49 & $216-366$ \\
\hline $18-19$ & 9 & 507 & 155 & $237-755$ & 4 & 302 & 17 & $291-327$ \\
\hline $20-24$ & 18 & 476 & 80 & $333-581$ & 15 & 311 & 67 & $169-455$ \\
\hline $25-29$ & 11 & 526 & 139 & $344-735$ & 10 & 303 & 68 & $165-414$ \\
\hline $30-34$ & 4 & 614 & 129 & $463-764$ & 2 & 334 & 27 & $314-353$ \\
\hline Total & 139 & & & & 98 & & & \\
\hline
\end{tabular}

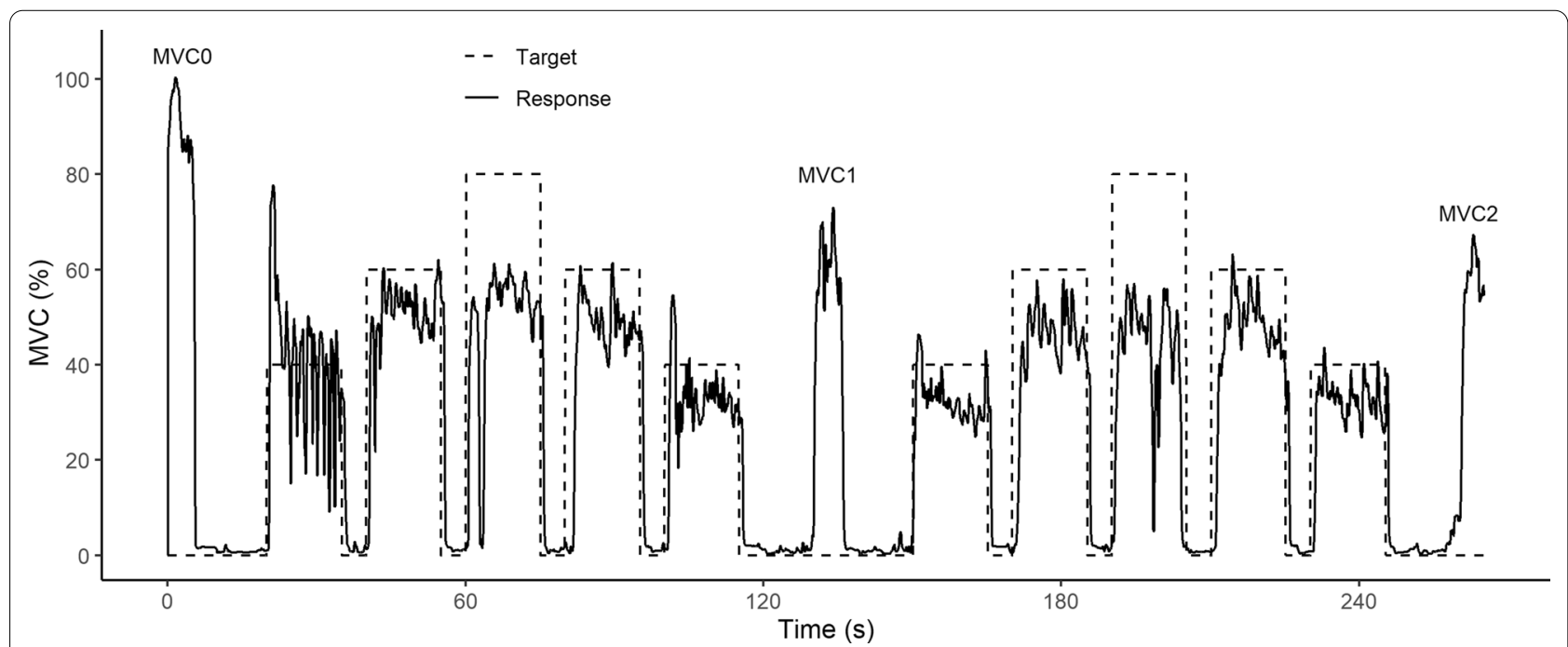

Fig. 4 Example of run data from a 9 year old male participant. Target is percent MVCO. MVCO, MVC1 and MVC2 indicate the three MVC tests during the game 
and $10-15$-s tracking periods at $40 \%, 60 \%$ and $80 \%$ of the initial MVC. The MVC for this participant was lower at the middle and end of the game. The participant had reasonable tracking at the $40 \%$ and $60 \%$ MVC levels but had difficulty tracking at the $80 \%$ level. This participant, like others, had an overshoot during the initial $40 \%$ tracking period as they were learning to control the rocket.

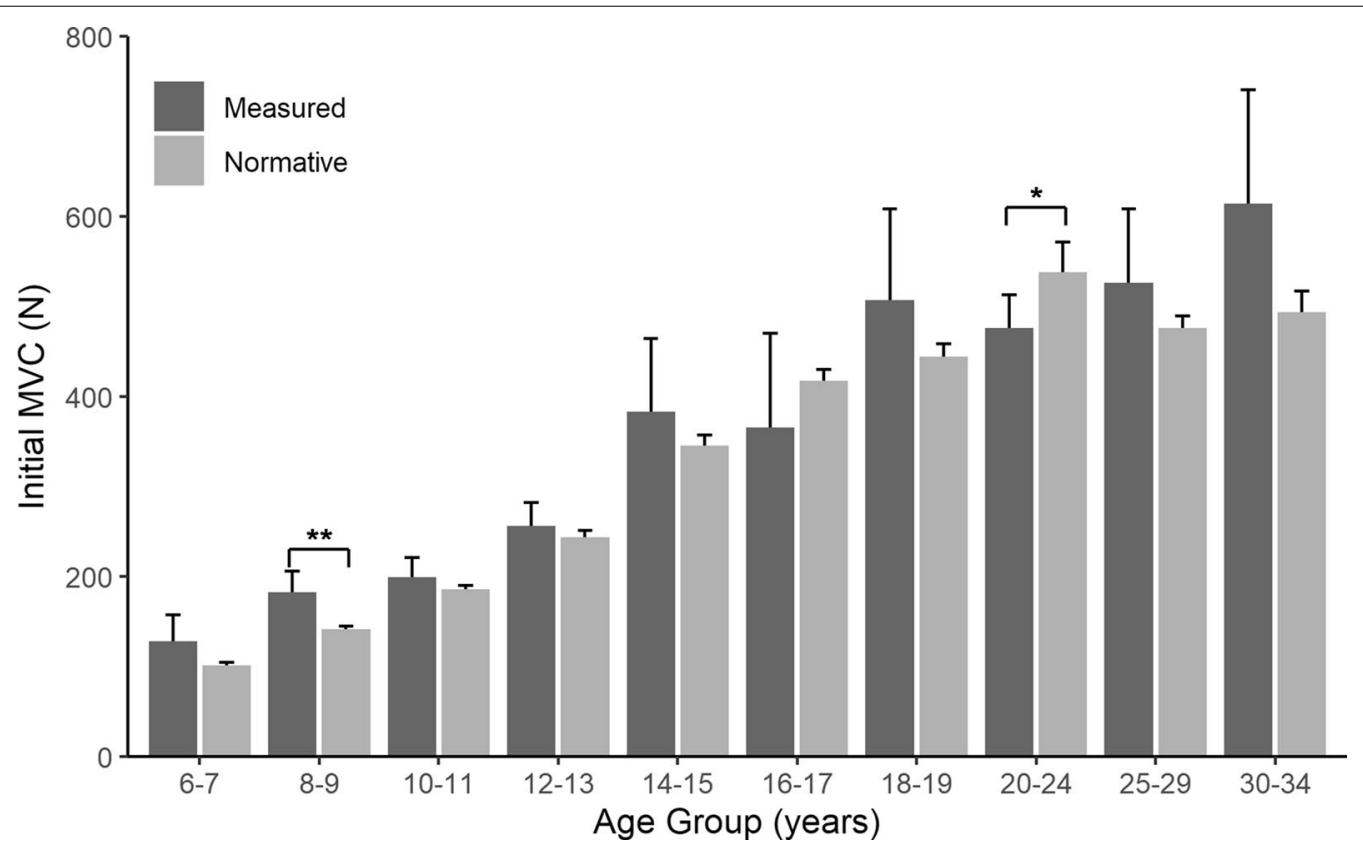

Fig. 5 MVCO (mean+95\%Cl) of male participants ( $n=139$, dark bars) compared to normative male data (light bars) from multiple sources [42, 43, 49-54], grouped by 2 year age ranges from 6 to 19 and 5 year age ranges from 20-34. Significant differences marked by*(p<.05) and **(p<.01)

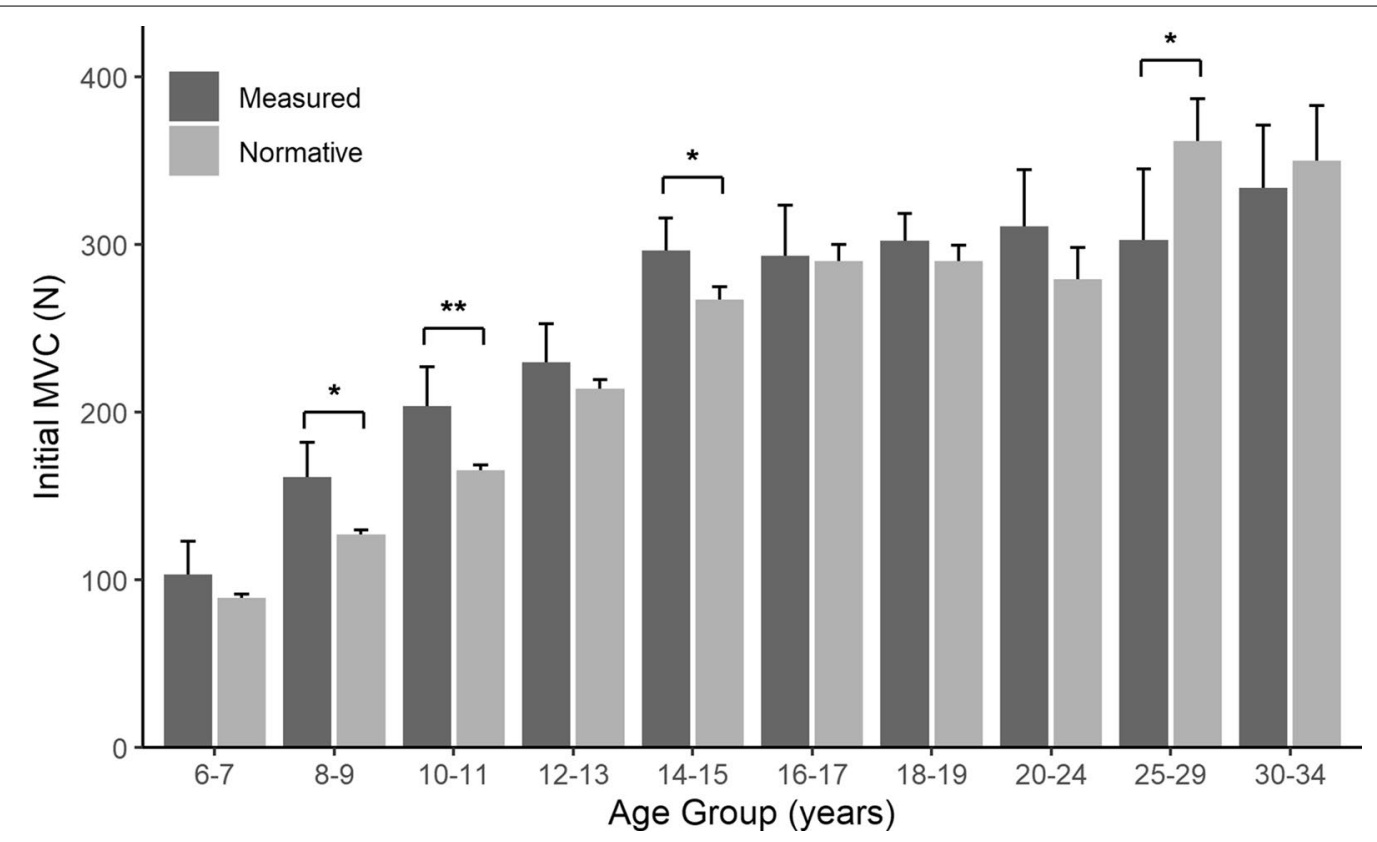

Fig. 6 MVCO (mean+95\%Cl) of female participants ( $n=98$, dark bars) and normative female data (light bars) from multiple sources [42, 43, 49-54], grouped by 2 year age ranges from 6-19 and 5 year age ranges from 20 to 34 . Significant differences marked by ${ }^{*}(p<.05)$ and ${ }^{* *}(p<.01)$ 


\section{Comparison of MVC to normative data}

Figures 5 and 6 show how the measured data from this study compares to normative data reported in the literature. For males (Fig. 5) ages 8-9 reported higher average MVC than the normative data $(\mathrm{p}<0.01)$ and ages 20-24 reported lower average MVC than the normative data $(\mathrm{p}<0.05)$. For females (Fig. 6) ages 8-9, 10-11 and 14-15 reported higher average MVC than the normative data $(\mathrm{p}<0.05, \mathrm{p}<0.01$ and $\mathrm{p}<0.05$ respectively) while ages 25-29 reported lower average MVC than the normative data set $(\mathrm{p}<0.05)$. The remaining 14 of the 20 age groups had the same average MVC between collected data and the normative data sets.

\section{Properties of MVC}

Figure 7 shows how MVC grip strength varied with the age of the participant. There was an increase in MVC0 as age increased for both male and female participants, which concurs with what is reported in the literature [42, 43, 49-54].

Most participants exhibited muscle fatigue as the game progressed. Figure 8 shows the average MVC across all participants for the pre-game, mid-game and post-game calibration periods. There were differences between the three $(\mathrm{F}(2,708)=335.8, \mathrm{p}<0.001)$. A post-hoc Bonferroni correction indicated that the initial MVC $(\mathrm{M}=100, \mathrm{SD}=0.0)$ was greater than the mid-game MVC $(M=80.2, S D=12.6)$ and the post-game MVC
$(\mathrm{M}=76.2, \mathrm{SD}=13.7)$, and that the mid-game $\mathrm{MVC}$ was greater than the post-game MVC with $\mathrm{p}<0.001$ for all comparisons. The same analysis was completed looking at males and females separately. For males there were differences between the pre-, mid- and post-game MVC $(\mathrm{F}(2,414)=196.5, \mathrm{p}<0.001)$ and a post-hoc Bonferroni correction indicated significant differences between all comparisons of pre-game MVC $(\mathrm{M}=100, \mathrm{SD}=0.0)$, mid-game $\mathrm{MVC}(\mathrm{M}=80.7, \mathrm{SD}=12.6)$ and post-game MVC $(M=75.2, S D=14.1)$ with $p<0.001$. Females showed differences between the three MVC values $(\mathrm{F}(2,291)=141.4, \mathrm{p}<0.001)$, with the post-hoc Bonferroni indicating that the initial $\mathrm{MVC}(\mathrm{M}=100, \mathrm{SD}=0.0)$ was greater than $(\mathrm{p}<0.001)$ the mid-game MVC $(M=79.4, S D=12.5)$ and post-game MVC $(M=77.5$, $\mathrm{SD}=12.9)$ but also indicating no difference between the mid- and post-game MVCs.

\section{Properties of tracking error}

Because we believe that tracking error over time as the muscle fatigues may reveal useful diagnostic information about those with muscle disease, we needed to understand whether tracking error is affected by MVC or by age for the non-impaired population. Figure 9 shows how tracking error varied with MVC0 and Fig. 10 shows how tracking error varied with age. Both show weak correlations (Pearson's $=0.22$ ).

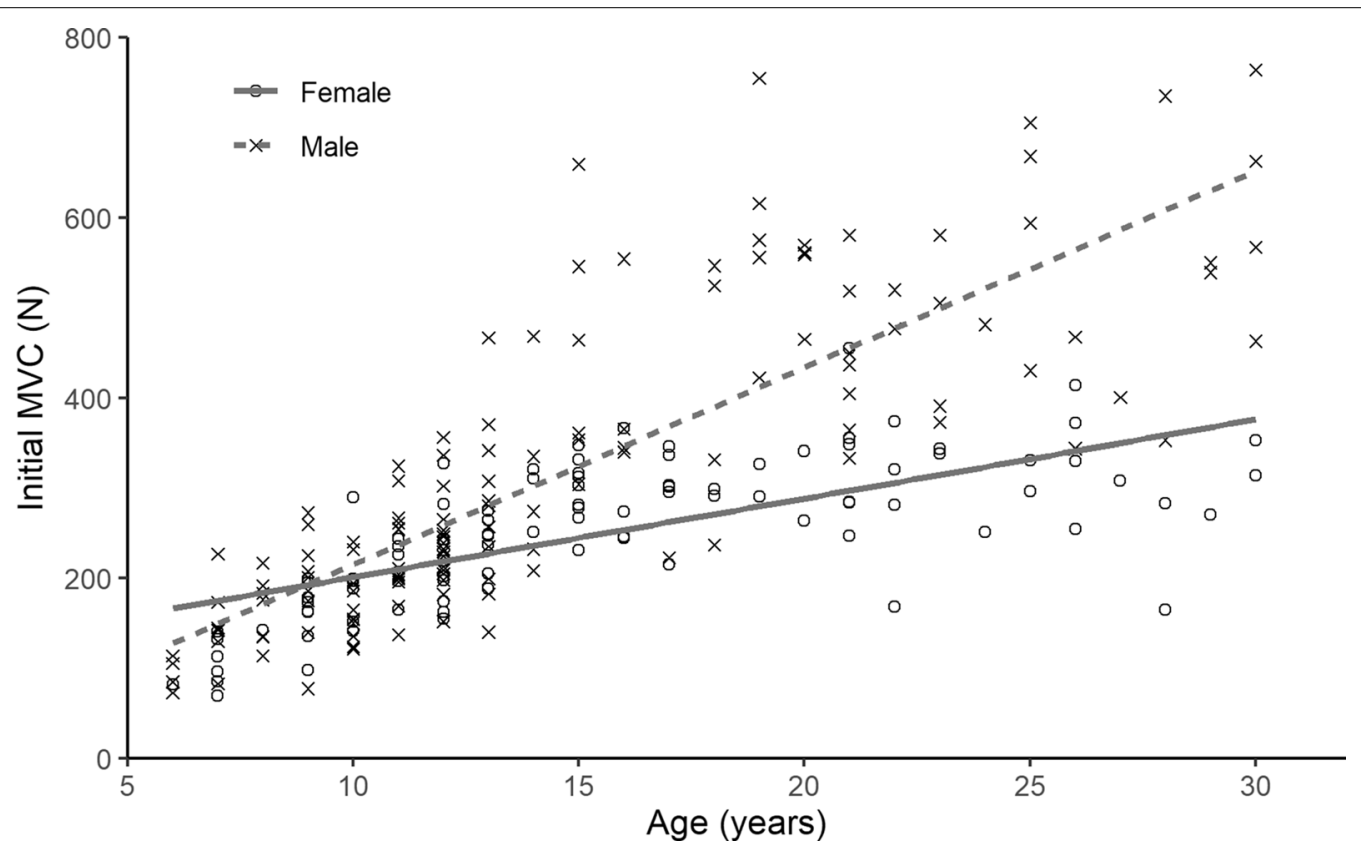

Fig. 7 Grip strength by age in a healthy population of males $(n=139)$ and females $(n=98)$ with trendlines for male $\left(r^{2}=0.67\right)$ and female $\left(r^{2}=0.46\right)$. The trendlines show that MVC increases with age for both genders 


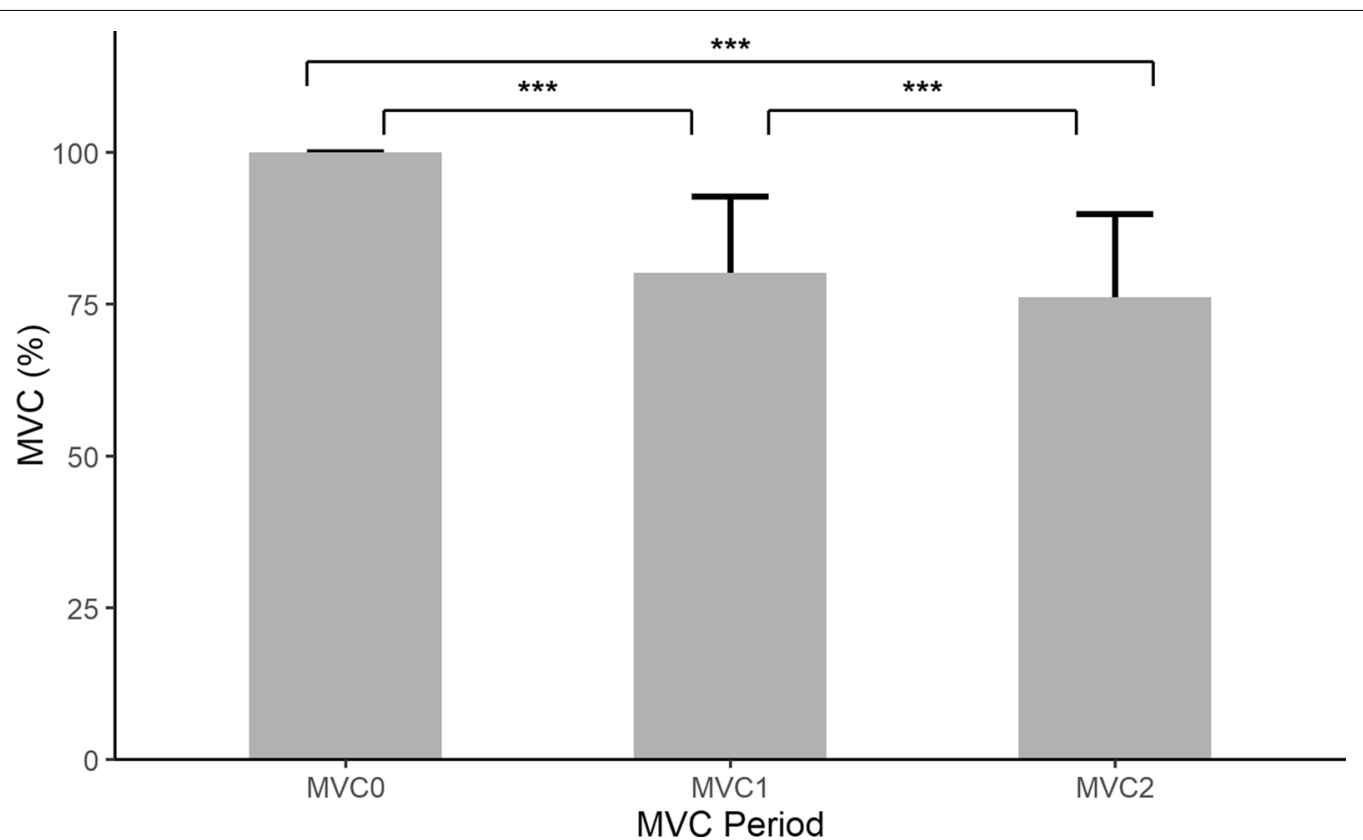

Fig. $8 \mathrm{MVC} \%$ (mean+SD) during MVCO $(M=100.0, S D=0.0), M V C 1(M=80.2, S D=12.6)$ and MVC2 $(M=76.2, S D=13.7)$ periods of gameplay in healthy population ( $N=237$ for each group). There was a significant difference between groups, $F(2,708)=335.8, p<.001$ with post hoc comparisons using Bonferroni correction indicated that all three groups were significantly different from each other $\left({ }^{* * *} p<0.001\right)$

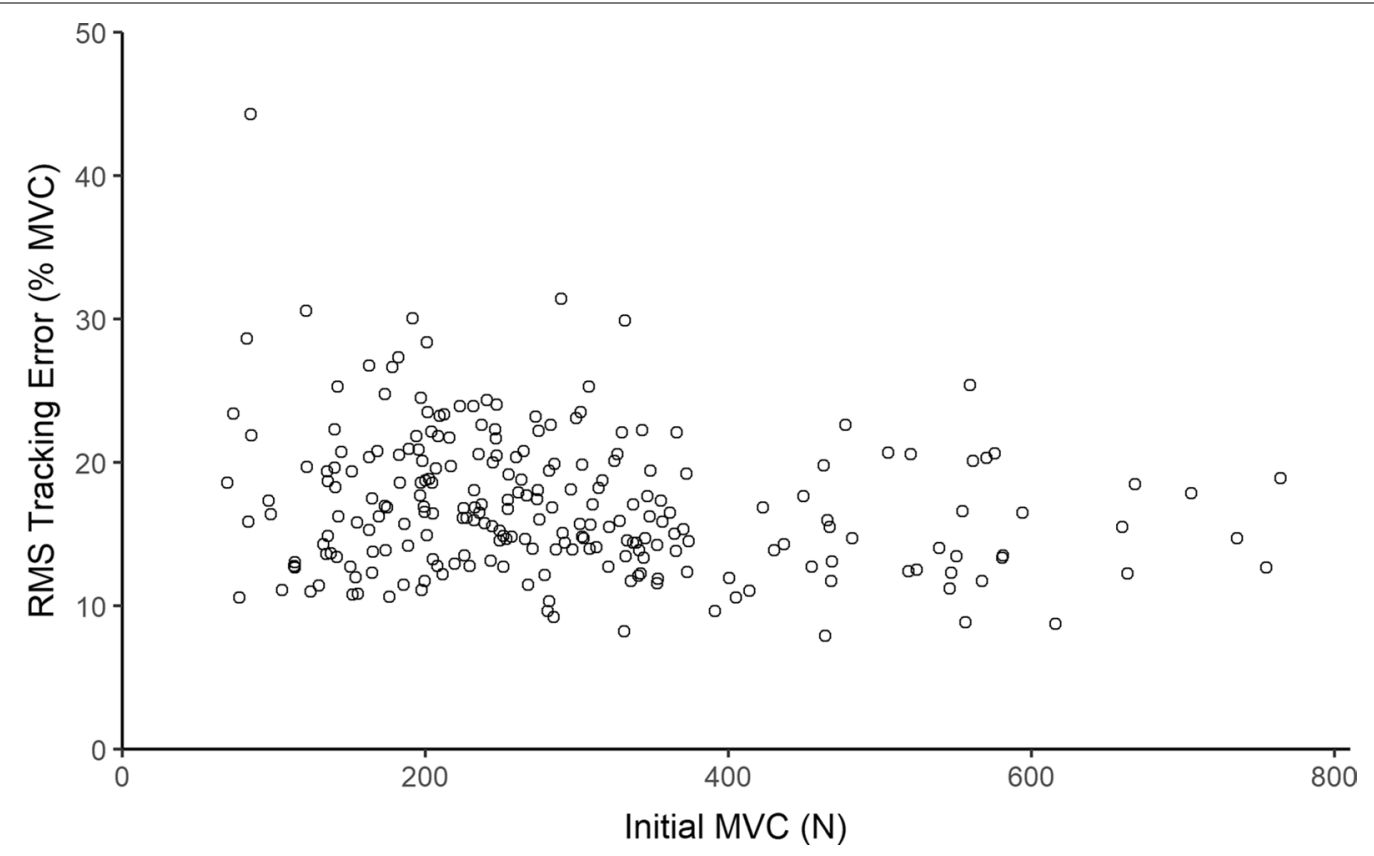

Fig. 9 RMS tracking error over the entire game by MVCO in a healthy population $(\mathrm{N}=237)$. The two variables are not strongly correlated, $r(235)=-0.22, p<0.001$ 


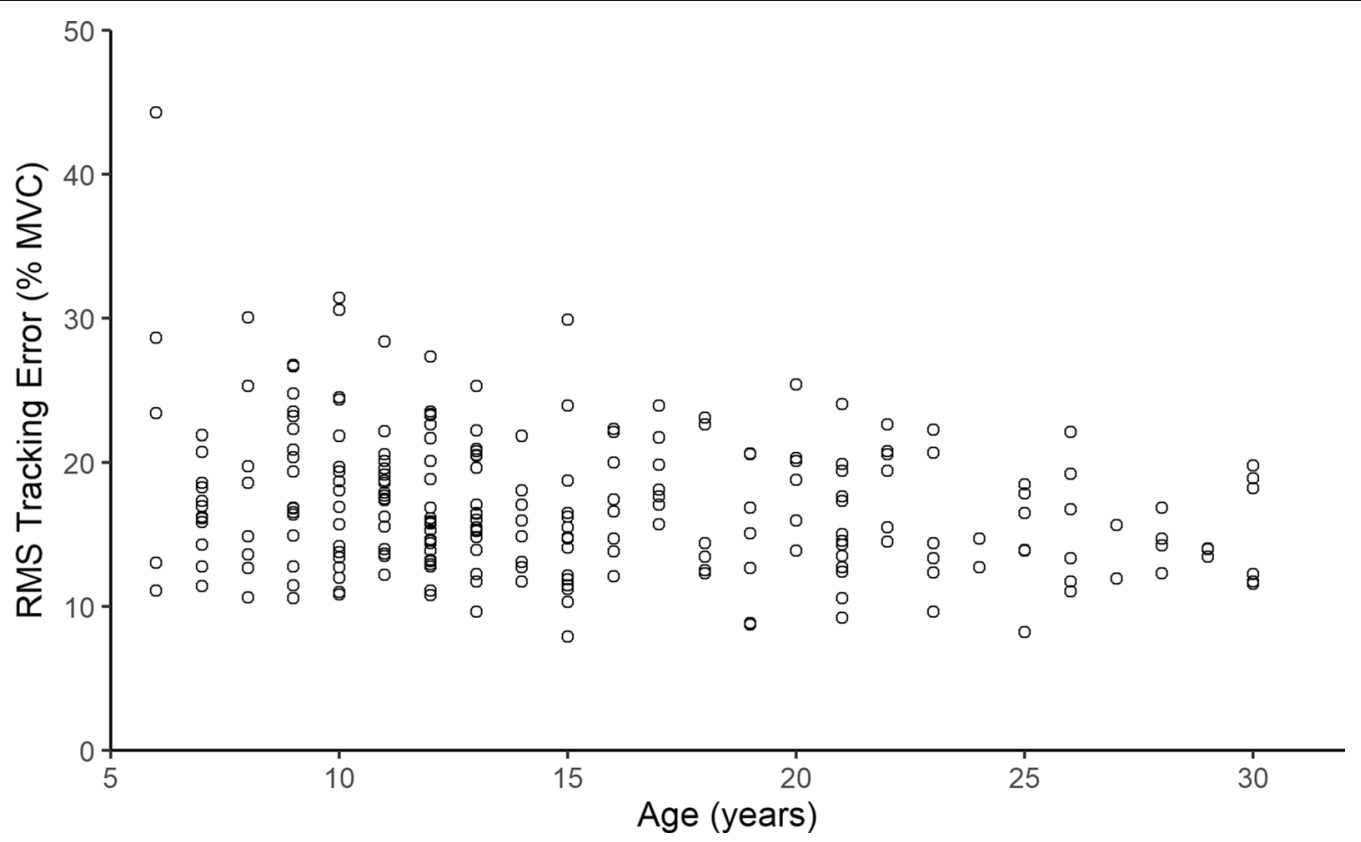

Fig. 10 RMS tracking error over the entire game by age in a healthy population $(N=237)$. The two variables are not strongly correlated, $r(235)=-0.22, p<0.001$

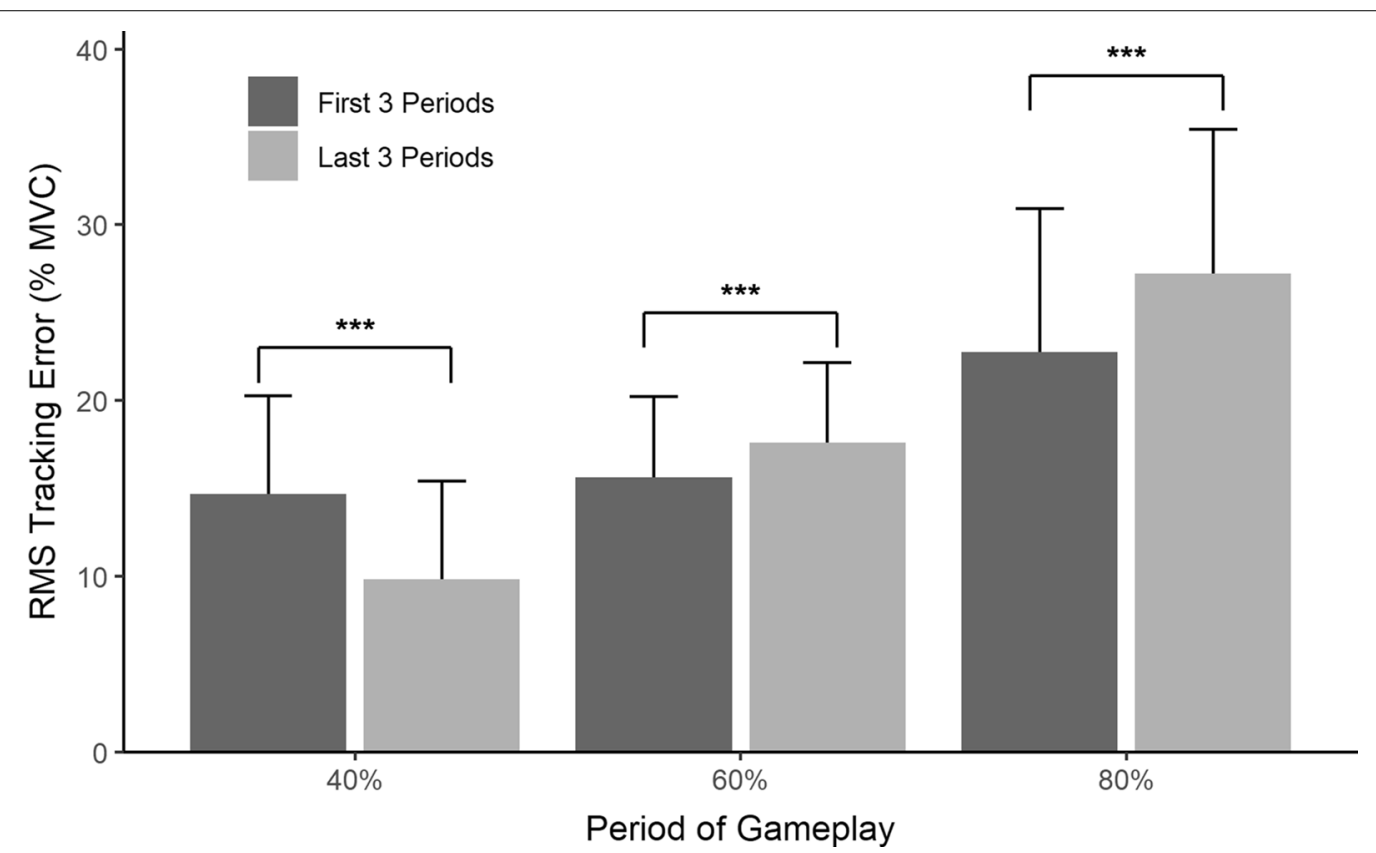

Fig. 11 Compares RMS tracking error (mean + SD) for the 1st and 2nd 40,60 and 80\% of MVC0 target periods in a non-impaired population ( $N=237$ in each group). For the 40\% MVCO target, tracking was better in the second half of the test while for the 60 and $80 \%$ MVCO targets, tracking was worse in the second half

Participants' tracking ability deteriorated at higher force levels as the game progressed. Figure 11 compares the RMS tracking error for 40,60 and $80 \%$ of MVCO target periods during the first and second halves of the game. Tracking error decreased for the $40 \%$ periods $(\mathrm{t}(236)=13.8, \mathrm{p}<0.001)$ but increased for the $60 \%$ $(\mathrm{t}(236)=-5.2, \mathrm{p}<0.001)$ and $80 \% \quad(\mathrm{t}(236)=-8.4$, $\mathrm{p}<0.001)$ periods. 
Both genders experienced the increase in $80 \%$ MVC tracking error. Males increased from the 1st $80 \%$ MVC tracking period $(\mathrm{M}=22.2, \mathrm{SD}=8.8)$ to the 2 nd $80 \%$ MVC tracking period $(\mathrm{M}=26.4, \mathrm{SD}=11.3)$, $(\mathrm{t}(138)=-6.1, \mathrm{p}<0.001)$. Females increased from the 1st $80 \%$ MVC tracking period $(\mathrm{M}=23.5, \mathrm{SD}=7.1)$ to the 2nd $80 \%$ MVC tracking period $(\mathrm{M}=28.4$, $\mathrm{SD}=10.8),(\mathrm{t}(97)=-5.8, \mathrm{p}<0.001)$.

\section{Participants with muscle disease}

Thirteen participants with muscle disease (ages 6 to 20, 9 male, 4 female) were enrolled and were assessed using the new device during one of their normal visits to the University of Minnesota Muscular Dystrophy Clinic. Of the 13, eight were diagnosed with Duchenne muscular dystrophy, one with Becker muscular dystrophy, one with congenital muscular dystrophy and three with spinal muscular atrophy. Seven were ambulatory and six used a wheelchair. Of the 13, all but one completed the game. Figure 12 shows an example of dynamometer grip force data from a 20 year old male with Duchenne muscular dystrophy. As with many of the non-diseased participants, there were oscillations during the initial $40 \%$ tracking period as the participant was learning to control the rocket. For this participant, MVC dropped as the game progressed and fatigue is evident during tracking at the second-half $80 \%$ level.

\section{Discussion}

The purpose of this study was to determine whether the hand grip device described in this paper produces grip strength measures that are consistent with normative data from the literature. A second purpose was to verify that participants are able to complete the fatiguing exercise protocol by playing a video game.

Because our hand grip system fatigues the user, we chose to compare the initial MVC values from our hand grip system to values reported in the literature rather than doing an experimental comparison to a traditional dynamometer such as the Jamar. If we had included a Jamar MVC in our measurements, the results would be contaminated by fatigue-induced order effects, particularly if participants played our fatiguing grip game first.

The results indicated that across males and females, 14 of 20 age groups had average MVC values that were the same as comparison data sets found in eight previous studies found in the literature. We chose to compare our data against all eight of the previous studies, including the widely cited studies by Mathiowetz [42, 43] because all eight used similar methods and all eight used a scientifically rigorous test protocol. The six age groups in our study that differed from the literature had differences that were small and in the same range as differences reported between previous studies. For example, when comparing data collected by Mathiowetz $[42,43]$ to six other studies using similar methods [49-54] we found that ten age groups had significantly different average MVC values. Because our device will primarily be used to track grip force changes over time in a single patient, any small differences in average MVC values found in our study compared to the MVC values found in the literature do not matter for the intended purpose of the device.

Unlike traditional hand grip tests, the new system takes the user through a more than four minute exercise protocol designed to induce fatigue. The reason for this is that we anticipate that fatigue profiles may reveal useful

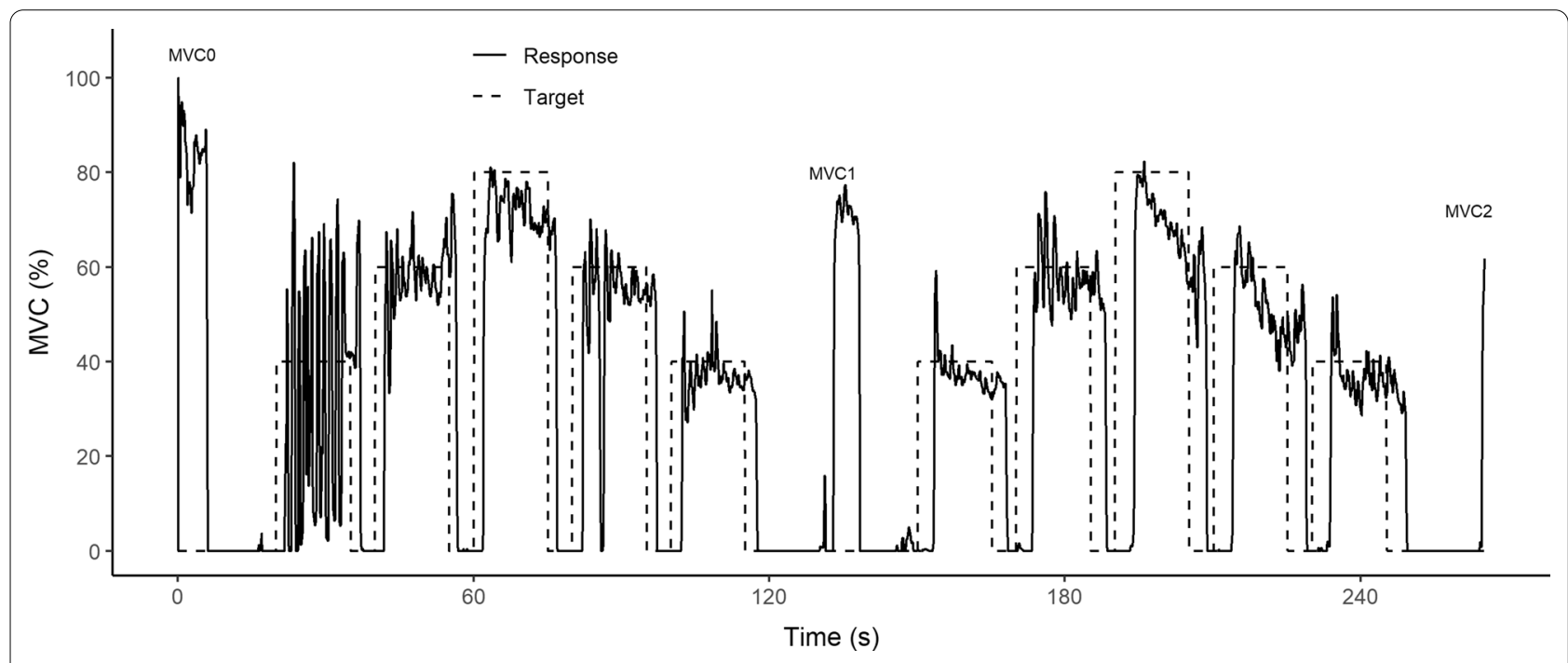

Fig. 12 Example of run data from a 20 year old male participant with Duchenne muscular dystrophy 
diagnostic information about children with neuromuscular disorders that goes beyond the information that can be gained from a single MVC reading. Our results for the pooled male and female data demonstrated that MVC decreased as the game progressed with maximum MVC at pre-game, a reduction at mid-game and the lowest at post-game, where MVC on average was $76 \%$ of the initial MVC. These results indicate that the exercise protocol did induce fatigue in a healthy population, a finding that was supported by talking with participants following their game session.

Tracking the higher force targets became more challenging during the second half of the game. For example, on average RMS tracking error increased by $19 \%$ during the second $80 \%$ MVC target period compared to the same target in the first half of the protocol. In contrast, tracking was better in the second half for the lower $40 \%$ MVC target (see Fig. 11). This was because most participants poorly tracked the first $40 \%$ target as they were learning to control the video game rocket by squeezing the dynamometer. For example, this is shown in the first tracking period in Fig. 4. This suggests that a brief get-toknow-the-game training period should be part of future protocols for diagnostic testing with the device.

At the higher force levels, the increased tracking error was mostly caused by muscle fatigue rather then by a loss of motor control. For the $80 \%$ target, 76 of the 237 participants were not able reach the first $80 \%$ target (average force of those 76 was $75 \%$ of MVC) while for the second $80 \%$ target, 135 participants were not able to reach the target (average force was 69\%). At the $40 \%$ level the better tracking during the second period was a learning effect as participants become more skilled at manipulating their squeezing and even when fatigued were able to reach $40 \%$ of their MVC.

We found that the RMS tracking error was independent of participant age and initial MVC in a population that had no neuromuscular disease. This indicates that while the main diagnostic measure is force at the beginning and end of the test, RMS tracking error could be a useful supplemental metric for disease state diagnosis or for tracking the effectiveness of a treatment program for those with muscular dystrophy. The utility of tracking error as a metric that is independent of force won't be known until data is collected from a large number of children with muscular dystrophy.

That all but one of the participants not only finished the game but also kept trying to earn points throughout the entire game, suggests that participants were motivated and engaged. (The one participant who did not finish the game put the controller down and walked away saying they did not want to continue playing the game). Because the game display kept a running total of points earned from observation it was clear that most participants were exerting their full strength during the calibration periods when MVC was recorded and during the tracking periods when RMS tracking error was recorded. Game points are normalized to initial MVC so that the total points scored is independent of absolute grip strength, which levels the playing field when participants play for points, providing additional motivation to engage.

While the main study used non-impaired participants by design, the intended patient population is children with neuromuscular disorders. While developing the prototype system, we conducted pilot tests using children with neuromuscular disorders and found that even children with weak grips were eager to play the game competitively against their non-affected siblings and parents. In addition, all but one of the 13 participants with muscle disease enrolled in the study reported here were able to complete the game indicating that the device is appropriate to assess muscle force in the intended patient population. The sample size of participants with muscle disease was too small to make any statements about changes in MVC or effects of fatigue. That information will be revealed when data collection from an ongoing clinical trial is complete.

There were several limitations to the study. First, it was difficult to determine in advance whether a participant should use the low-force or high-force dynamometer. Several were erroneously given the low-force dynamometer, which resulted in the large number $(\mathrm{N}=39)$ of data records that could not be used due to saturation of the force transducer. The age range of those who saturated the low-force system was 13 to $30(M=20.8, S D=4.7)$, which suggests they should have been given the highforce system right away. To eliminate this problem, the next generation system will have a single hand grip and will have software that automatically adjust the gain, which will eliminate the force saturation problem. Second, due to ongoing revisions in the software, several $(\mathrm{N}=27)$ sessions had missing data and could not be used. Despite this, the data set used for analysis $(\mathrm{N}=237)$ was sufficiently large to validate the device. Third, while the dynamometer is lightweight, initial studies in patients with neuromuscular disease demonstrate that it is still too heavy for use by those with low arm and grip strength. We are currently revising the design so that the dynamometer is supported, which means the user does not have to support the weight of the device.

\section{Conclusion}

Traditional measures of hand grip strength for monitoring muscle function in children with neuromuscular diseases offer no motivation for the child to exert maximum effort during the test and do not include a way to measure 
function as the muscle fatigues. The hand grip device described in this paper is intended to overcome both of these limitations. Our results show that the new device is valid when compared to normative data on hand grip forces reported in the literature. While the main study had non-impaired participants, from the initial results with the intended patient population we expect that the new device will be a reliable quantitative measuring tool for assessing muscle function in children with neuromuscular diseases including children with muscular dystrophy.

\begin{abstract}
Abbreviations
DMD: Duchenne muscular dystrophy; MMT: Manual muscle test; QMT: Quantitative muscle testing; 6MWT: Six-minute walk test; NSAA: North Star Ambulatory Assessment; PUL: Performance of the Upper Limb; MVC: Maximal voluntary contraction; MVCO: Beginning MVC; MVC1: Middle MVC; MVC2: Ending MVC; RMS: Root mean square; M: Mean; SD: Standard deviation; ANOVA: Analysis of variance.
\end{abstract}

\section{Acknowledgements}

The authors thank Allison Schmitz, Bhargavi Rangan, Dena Sloan, Elsa Hauschildt, Ibrahim Yekinni, Lyndsey Calvin, Natalie Vig, Rachel Anderson, Samantha Lee, Stuart Bennett and Vikram Katti, all University of Minnesota students who spent long hours at the 2018 Minnesota State Fair collecting data. We also thank the University of Minnesota Driven to Discover Research Facility staff for facilitating the data collection process. We thank our clinical partners Joline Dalton, Peter Karachunski, and Molly Stark for helpful discussions regarding the unmet clinical need.

\section{Authors' contributions}

MG performed all of the data analysis, created the figures and wrote significant portions of the manuscript. DT and WD conceived the hand grip device, planned the study and directed the data analysis. WD directed the engineering of the device and was the lead on the evaluation study. All authors read and approved the final manuscript.

\section{Funding}

This study was funded by grants from the Greg Marzolf Jr. Foundation.

\section{Data availability statement}

The de-identified dataset analysed for the current study is available from the corresponding author on reasonable request.

\section{Declarations}

Ethics approval and consent to participate

The study was approved by the University of Minnesota Institutional Review Board, IRB ID: STUDY00003448 and IRB ID: STUDY00001330. All participants consented to be in the study.

\section{Consent for publication}

Consent was obtained for images used in the manuscript.

\section{Competing interests}

The authors declare that they have no competing interests.

\section{Author details}

'Department of Mechanical Engineering, University of Minnesota, Minneapolis, USA. ${ }^{2}$ Department of Integrative Biology and Physiology, University of Minnesota, Minneapolis, USA.

Received: 10 November 2020 Accepted: 28 June 2021

Published online: 10 July 2021

\section{References}

1. Mercuri E, Muntoni F. Muscular dystrophies. Lancet. 2013;381(9869):845-60.

2. Hoffman EP, Brown RH, Kunkel LM. Dystrophin: the protein product of the Duchenne muscular dystrophy locus. Cell. 1987;51(6):919-28.

3. Romitti PA, Zhu Y, Puzhankara S, James KA, Nabukera SK, Zamba GKD, Ciafaloni E, Cunniff C, Druschel CM, Mathews KD, Matthews DJ, Meaney FJ, Andrews JG, Caspers Conway KM, Fox DJ, Street N, Adams MM, Bolen J. Prevalence of duchenne and becker muscular dystrophies in the united states. Pediatrics. 2015;135(3):513-21.

4. MedlinePlus: Duchenne muscular dystrophy: MedlinePlus Medical Encyclopedia (2019). http://www.nlm.nih.gov/medlineplus/ency/article/ 000705.htm Accessed 2021-05-01

5. Bushby K, Finkel R, Birnkrant DJ, Case LE, Clemens PR, Cripe L, Kaul A, Kinnett K, McDonald C, Pandya S, Poysky J, Shapiro F, Tomezsko J, Constantin C. DMD Care Considerations Working Group: Diagnosis and management of Duchenne muscular dystrophy, part 1: diagnosis, and pharmacological and psychosocial management. Lancet. 2010;9(1):77-93.

6. Bushby K, Finkel R, Birnkrant DJ, Case LE, Clemens PR, Cripe L, Kaul A, Kinnett K, McDonald C, Pandya S, Poysky J, Shapiro F, Tomezsko J, Constantin C. DMD Care Considerations Working Group: Diagnosis and management of Duchenne muscular dystrophy, part 2: implementation of multidisciplinary care. Lancet. 2010;9(2):177-89.

7. Guiraud S, Aartsma-Rus A, Vieira NM, Davies KE, van Ommen G-JB, Kunkel LM. The pathogenesis and therapy of muscular dystrophies. Annu Rev Genomics Hum Genet. 2015;16:281-308.

8. Kang PB, Morrison L, lannaccone ST, Graham RJ, Bonnemann CG, Rutkowski A, Hornyak J, Wang CH, North K, Oskoui M, Getchius TSD, Cox JA, Hagen EE, Gronseth G, Griggs RC. Evidence-based guideline summary: evaluation, diagnosis, and management of congenital muscular dystrophy: report of the Guideline Development Subcommittee of the American Academy of Neurology and the Practice Issues Review Panel of the American Association of Neuromuscular \& Electrodiagnostic Medicine. Neurology. 2015;84(13):1369-78.

9. Bushby K, Muntoni F, Urtizberea A, Hughes R, Griggs R. Report on the 124th ENMC International Workshop. Treatment of Duchenne muscular dystrophy; defining the gold standards of management in the use of corticosteroids. 2-4 April 2004, Naarden, The Netherlands. Neuromuscular disorders: NMD 2004; 14(8-9): 526-534

10. Spurney CF, Rocha CT, Henricson E, Florence J, Mayhew J, Gorni K, Pasquali L, Pestronk A, Martin GR, Hu F, Nie L, Connolly AM, Escolar DM. Cooperative International Neuromuscular Research Group Investigators: CINRG pilot trial of coenzyme Q10 in steroid-treated Duchenne muscular dystrophy. Muscle Nerve. 2011;44(2):174-8.

11. McDonald CM, Henricson EK, Abresch RT, Florence JM, Eagle M, Gappmaier E, Glanzman AM, PTC124-GD-007-DMD Study Group, Spiegel R, Barth J, Elfring G, Reha A, Peltz S. The 6-minute walk test and other endpoints in Duchenne muscular dystrophy: longitudinal natural history observations over 48 weeks from a multicenter study. Muscle \& Nerve. 2013;48(3):343-56.

12. McDonald CM, Henricson EK, Abresch RT, Florence J, Eagle M, Gappmaier E, Glanzman AM, PTC124-GD-007-DMD Study Group, Spiegel R, Barth J, Elfring G, Reha A, Peltz SW. The 6-minute walk test and other clinical endpoints in duchenne muscular dystrophy: reliability, concurrent validity, and minimal clinically important differences from a multicenter study. Muscle \& Nerve. 2013;48(3):357-68.

13. McDonald CM, Henricson EK, Han JJ, Abresch RT, Nicorici A, Elfring GL, Atkinson L, Reha A, Hirawat S, Miller LL. The 6-minute walk test as a new outcome measure in Duchenne muscular dystrophy. Muscle Nerve. 2010:41(4):500-10.

14. Scott E, Eagle M, Mayhew A, Freeman J, Main M, Sheehan J, Manzur A, Muntoni F. North Star Clinical Network for Paediatric Neuromuscular Disease: Development of a functional assessment scale for ambulatory boys with Duchenne muscular dystrophy. Physiother Res Int. 2012;17(2):101-9.

15. Mazzone E, Martinelli D, Berardinelli A, Messina S, D'Amico A, Vasco G, Main M, Doglio L, Politano L, Cavallaro F, Frosini S, Bello L, Carlesi A, Bonetti AM, Zucchini E, De Sanctis R, Scutifero M, Bianco F, Rossi F, Motta MC, Sacco A, Donati MA, Mongini T, Pini A, Battini R, Pegoraro E, Pane M, Pasquini E, Bruno C, Vita G, de Waure C, Bertini E, Mercuri E. North Star Ambulatory Assessment, 6-minute walk test and timed items in 
ambulant boys with Duchenne muscular dystrophy. Neuromusc Disorders. 2010;20(11):712-6.

16. Connolly AM, Florence JM, Cradock MM, Malkus EC, Schierbecker JR, Siener CA, Wulf CO, Anand P, Golumbek PT, Zaidman CM, Philip Miller J, Lowes LP, Alfano LN, Viollet-Callendret L, Flanigan KM, Mendell JR, McDonald CM, Goude E, Johnson L, Nicorici A, Karachunski PI, Day JW, Dalton JC, Farber JM, Buser KK, Darras BT, Kang PB, Riley SO, Shriber E, Parad R, Bushby K, Eagle M. MDA DMD Clinical Research Network: Motor and cognitive assessment of infants and young boys with Duchenne Muscular Dystrophy: results from the Muscular Dystrophy Association DMD Clinical Research Network. Neuromusc Disorders. 2013;23(7):529-39.

17. Mazzone ES, Messina S, Vasco G, Main M, Eagle M, DAmico A, Doglio L, Politano L, Cavallaro F, Frosini S, Bello L, Magri F, Corlatti A, Zucchini E, Brancalion B, Rossi F, Ferretti M, Motta MG, Cecio MR, Berardinelli A, Alfieri P, Mongini T, Pini A, Astrea G, Battini R, Comi G, Pegoraro E, Morandi L, Pane M, Angelini C, Bruno C, Villanova M, Vita G, Donati MA, Bertini E, Mercuri E. Reliability of the North Star Ambulatory Assessment in a multicentric setting. Neuromusc Disorders 2009;19(7):458-61.

18. De Sanctis R, Pane M, Sivo S, Ricotti V, Baranello G, Frosini S, Mazzone E, Bianco F, Fanelli L, Main M, Corlatti A, D'Amico A, Colia G, Scalise R, Palermo C, Alfonsi C, Tritto G, Romeo DM, Graziano A, Battini R, Morandi L, Bertini E, Muntoni F, Mercuri E. Suitability of North Star Ambulatory Assessment in young boys with Duchenne muscular dystrophy. Neuromuscular disorders: NMD. 2015;25(1):14-8.

19. Lerario A, Bonfiglio S, Sormani M, Tettamanti A, Marktel S, Napolitano S, Previtali S, Scarlato M, Natali-Sora M, Mercuri E, Bresolin N, Mongini T, Comi G, Gatti R, Ciceri F, Cossu G, Torrente Y. Quantitative muscle strength assessment in duchenne muscular dystrophy: longitudinal study and correlation with functional measures. BMC Neurol. 2012;12:91.

20. Mayhew JE, Florence JM, Mayhew TP, Henricson EK, Leshner RT, McCarter RJ, Escolar DM. Reliable surrogate outcome measures in multicenter clinical trials of Duchenne muscular dystrophy. Muscle \& Nerve. 2007;35(1):36-42.

21. Connolly AM, Malkus EC, Mendell JR, Flanigan KM, Miller JP, Schierbecker JR, Siener CA, Golumbek PT, Zaidman CM, Mcdonald CM, Johnson L Nicorici A, Karachunski PI, Day JW, Kelecic JM, Lowes LP, Alfano LN, Darras BT, Kang PB, Quigley J, Pasternak AE, Florence JM. MDA DMD Clinical Research Network: Outcome reliability in non-ambulatory boys/men with Duchenne muscular dystrophy. Muscle \& Nerve. 2015;51(4):522-32.

22. Escolar DM, Henricson EK, Mayhew J, Florence J, Leshner R, Patel KM, Clemens PR. Clinical evaluator reliability for quantitative and manual muscle testing measures of strength in children. Muscle \& Nerve. 2001;24(6):787-93.

23. Scott E, Mawson SJ. Measurement in Duchenne muscular dystrophy: considerations in the development of a neuromuscular assessment tool. Dev Med Child Neurol. 2006:48(6):540-4.

24. Bushby K, Connor E. Clinical outcome measures for trials in Duchenne muscular dystrophy: report from International Working Group meetings. Clinical Investigation. 2011;1 (9):1217-35.

25. Mazzone ES, Vasco G, Palermo C, Bianco F, Galluccio C, Ricotti V, Castronovo AD, Mauro MSDI, Pane M, Mayhew A, Mercuri E. A critical review of functional assessment tools for upper limbs in Duchenne muscular dystrophy. Dev Med Child Neurol. 2012;54(10):879-85.

26. Petitclerc E, Hebert LJ, Desrosiers J, Gagnon C. Lower limb muscle impairment in myotonic dystrophy type 1: The need for better guidelines. Muscle \& Nerve. 2015;51(4):473-8.

27. Clarkson HM. Musculoskeletal Assessment: Joint Range of Motion and Manual Muscle Strength. New York: Lippincott Williams and Wilkins; 2000

28. Hislop H, Avers D, Brown M. Daniels and Worthingham's Muscle Testing: Techniques of Manual Examination and Performance Testing. New York: Elsevier Health Sciences; 2013.

29. Iddings DM, Smith LK, Spencer WA. Muscle testing: Part 2. reliability in clinical use. Phys Ther. 1961;41:249-56.

30. Schwartz S, Cohen ME, Herbison GJ, Shah A. Relationship between two measures of upper extremity strength: Manual muscle test compared to hand-held myometry. Arch Phys Med Rehabil. 1992;73(11):1063-8.

31. Whittaker RG, Ferenczi E, Hilton-Jones D. Myotonic dystrophy: practical issues relating to assessment of strength. J Neurol Neurosurg Psychiatry. 2006;77(11):1282-3.
32. Amundsen LR. Muscle Strength Testing: Instrumented and Non-Instrumented Systems. New York: Churchill Livingstone; 1990.

33. Bohannon RW. Test-retest reliability of hand-held dynamometry during a single session of strength assessment. Phys Ther. 1986;66(2):206-9.

34. Bohannon RW, Andrews AW. Interrater reliability of hand-held dynamometry. Phys Ther. 1987;67(6):931-3.

35. Iannaccone ST. American Spinal Muscular Atrophy Randomized Trials (AmSMART) Group: Outcome measures for pediatric spinal muscular atrophy. Arch Neurol. 2002;59(9):1445-50.

36. ATS Committee on Proficiency Standards for Clinical Pulmonary Function Laboratories: ATS statement: guidelines for the six-minute walk test. American Journal of Respiratory and Critical Care Medicine. 2002;166(1):111-7.

37. Enright PL. The six-minute walk test. Respir Care. 2003;48(8):783-5.

38. Mayhew A, Mazzone ES, Eagle M, Duong T, Ash M, Decostre V, Vandenhauwe M, Klingels K, Florence J, Main M, Bianco F, Henrikson E, Servais L, Campion G, Vroom E, Ricotti V, Goemans N, McDonald C, Mercuri E. Performance of the Upper Limb Working Group: Development of the Performance of the Upper Limb module for Duchenne muscular dystrophy. Dev Med Child Neurol. 2013;55(11):1038-45.

39. Pane M, Mazzone ES, Sivo S, Fanelli L, De Sanctis R, D’Amico A, Messina S, Battini R, Bianco F, Scutifero M, Petillo R, Frosini S, Scalise R, Vita GL, Bruno C, Pedemonte M, Mongini T, Pegoraro E, Brustia F, Gardani A, Berardinelli A, Lanzillotta V, Viggiano E, Cavallaro F, Sframeli M, Bello L, Barp A, Busato F, Bonfiglio S, Rolle E, Colia G, Bonetti A, Palermo C, Graziano A, D'Angelo G, Pini A, Corlatti A, Gorni K, Baranello G, Antonaci L, Bertini E, Politano $L$, Mercuri E. The 6 minute walk test and performance of upper limb in ambulant duchenne muscular dystrophy boys. PLoS currents. 2014;6.

40. Pane M, Mazzone ES, Fanelli L, De Sanctis R, Bianco F, Sivo S, D'Amico A, Messina S, Battini R, Scutifero M, Petillo R, Frosini S, Scalise R, Vita G, Bruno C, Pedemonte M, Mongini T, Pegoraro E, Brustia F, Gardani A, Berardinelli A, Lanzillotta V, Viggiano E, Cavallaro F, Sframeli M, Bello L, Barp A, Bonfiglio S, Rolle E, Colia G, Catteruccia M, Palermo C, D'Angelo G, Pini A, lotti E, Gorni K, Baranello G, Morandi L, Bertini E, Politano L, Sormani M, Mercuri E. Reliability of the Performance of Upper Limb assessment in Duchenne muscular dystrophy. Neuromuscular disorders: NMD. 2014;24(3):201-6.

41. Mattar FL, Sobreira C. Hand weakness in Duchenne muscular dystrophy and its relation to physical disability. Neuromuscular disorders: NMD. 2008:18(3):193-8.

42. Mathiowetz V, Wiemer DM, Federman SM. Grip and pinch strength: norms for 6- to 19-year-olds. Am J Occup Ther. 1986;40(10):705-11.

43. Mathiowetz V, Kashman N, Volland G, Weber K, Dowe M, Rogers S. Grip and pinch strength: normative data for adults. Arch Phys Med Rehabil. 1985;66(2):69-74

44. Thomas GD, Sander M, Lau KS, Huang PL, Stull JT, Victor RG. Impaired metabolic modulation of alpha-adrenergic vasoconstriction in dystrophin-deficient skeletal muscle. Proc Natl Acad Sci USA. 1998;95(25):15090-5.

45. Sander M, Chavoshan B, Harris SA, lannaccone ST, Stull JT, Thomas GD, Victor RG. Functional muscle ischemia in neuronal nitric oxide synthasedeficient skeletal muscle of children with Duchenne muscular dystrophy. Proc Natl Acad Sci USA. 2000;97(25):13818-23.

46. Kobayashi YM, Rader EP, Crawford RW, lyengar NK, Thedens DR, Faulkner JA, Parikh SV, Weiss RM, Chamberlain JS, Moore SA, Campbell KP. Sarcolemma-localized nNOS is required to maintain activity after mild exercise. Nature. 2008;456(7221):511-5.

47. Pangalila RF, Van Den Bos GA, Bartels B, Bergen M, Stam HJ, Roebroeck ME. Prevalence of fatigue, pain, and affective disorders in adults with duchenne muscular dystrophy and their associations with quality of life. Arch Phys Med Rehabil. 2015;96(7):1242-7.

48. Montes J, Blumenschine M, Dunaway S, Alter AS, Engelstad K, Rao AK, Chiriboga CA, Sproule DM, De Vivo DC. Weakness and fatigue in diverse neuromuscular diseases. J Child Neurol. 2013;28(10):1277-83.

49. Omar MTA, Alghadir A, Al Baker S. Norms for hand grip strength in children aged 6-12 years in saudi arabia. Dev Neurorehabil. 2015;18(1):59-64.

50. Yim SY, Cho JR, Lee IY. Normative data and developmental characteristics of hand function for elementary school children in Suwon area of Korea: Grip, pinch and dexterity study. J Korean Med Sci. 2003;18(4):552-8.

51. Ager $\mathrm{CL}$, Olivett $\mathrm{BL}$, Johnson $\mathrm{CL}$. Grasp and pinch strength in children 5 to 12 years old. The American journal of occupational therapy: 
official publication of the American Occupational Therapy Association. 1984;38(2):107-13.

52. Fain $E$, Weatherford C. Comparative study of millennials' (age 20-34 years) grip and lateral pinch with the norms. J Hand Ther. 2016;29(4):483-8.

53. Hager-Ross C, Rosblad B. Norms for grip strength in children aged 4-16 years. Acta Paediatrica, International Journal of Paediatrics. 2002;91(6):617-25.

54. McQuiddy VA, Scheerer CR, Lavalley R, McGrath T, Lin L. Normative values for grip and pinch strength for 6- to 19-year-olds. Arch Phys Med Rehabil. 2015;96(9):1627-33.
55. R Core Team: R: A Language and Environment for Statistical Computing. R Foundation for Statistical Computing, Vienna, Austria (2020). R Foundation for Statistical Computing. https://www.R-project.org/

\section{Publisher's Note}

Springer Nature remains neutral with regard to jurisdictional claims in published maps and institutional affiliations.
Ready to submit your research? Choose BMC and benefit from:

- fast, convenient online submission

- thorough peer review by experienced researchers in your field

- rapid publication on acceptance

- support for research data, including large and complex data types

- gold Open Access which fosters wider collaboration and increased citations

- maximum visibility for your research: over $100 \mathrm{M}$ website views per year

At BMC, research is always in progress.

Learn more biomedcentral.com/submissions 